\title{
PAPER
}

Cite this: J. Mater. Chem. B, 2017 5, 2931

\section{The physics and chemistry of silica-in-silicates nanocomposite hydrogels and their phycocompatibility $\dagger$}

\author{
Nada Ben Ahmed, ${ }^{\text {ab }}$ Olivier Ronsin, ${ }^{c}$ Ludovic Mouton, ${ }^{b}$ Clémence Sicard, ${ }^{d}$ \\ Claude Yéprémian, ${ }^{e}$ Tristan Baumberger, ${ }^{c}$ Roberta Brayner*b and \\ Thibaud Coradin (D) *a
}

\begin{abstract}
Silicates-in-silica nanocomposite hydrogels obtained from sodium silicates/colloidal silica mixtures have previously been found to be useful for bacterial encapsulation. However the extension of synthesis conditions and the understanding of their impact on the silica matrix would widen the applicability of this process in terms of encapsulated organisms and the host properties. Here the influence of silicates and the colloidal silica concentration as well as $\mathrm{pH}$ conditions on the gel time, the optical properties, the structural and mechanical properties of silica matrices was studied. We show that gel formation is driven by silicate condensation but that the aggregation of silica colloids also has a major influence on the transparency and structure of the nanocomposites. Three different photosynthetic organisms, cyanobacteria Anabaena flos-aquae and two microalgae Chorella vulgaris and Euglena gracilis, were used as probes of the phycocompatibility of the process. The three organisms were highly sensitive to the silicate concentration, which impacts both the gelation time and ionic strength conditions. The Ludox content was crucial for cyanobacteria as it strongly impacts the Young's modulus of the matrices. The detrimental effect of acidic pH on cell suspension was compensated by the silica network. Overall, it is now possible to select optimal encapsulation conditions based on the physiology of the targeted cells, opening wide perspectives for the design of biosensors and bioreactors.
\end{abstract}

Received 2nd February 2017, Accepted 20th March 2017

DOI: 10.1039/c7tb00341b cell diffusion issues that can slow down, if not hinder, the full colonization of the host. ${ }^{3,4}$ Moreover, this approach leads to an easy leaching of the cells out of the matrix, which can be advantageous for biomaterials, ${ }^{5}$ but unsuitable for bioreactor or biosensor design. ${ }^{6,7}$ However it has the advantage of being applicable to almost all types of materials, provided that they do not release harmful products and that no detrimental interactions occur between the host surface and the cells. ${ }^{8}$

The alternative strategy is the encapsulation of the living organisms within a 3D material during its formation. ${ }^{9}$ This approach should guarantee the stable entrapment of the cells in the absence of external stresses or internal biodegradation. However it raises important challenges in terms of chemistry as the conditions of matrix formation must be compatible with the survival of the organisms. Basically the encapsulation reaction involves a precursor (that can be a single or a mixture of organic monomers, metal species or polymer chains) in water (that is the only acceptable solvent for a wide majority of cells) that undergoes a solidification process under physical (temperature and light), physico-chemical ( $\mathrm{pH}$ and ionic strength) and/or chemical (cross-linker) activation. ${ }^{10-12}$ In this context, silica hydrogels appear to be particularly attractive

\footnotetext{
Sorbonne Universités, UPMC Univ Paris 06, CNRS, Collège de France, UMR 7574, F-75005 Paris, France. E-mail: thibaud.coradin@upmc.fr

${ }^{b}$ Sorbonne Paris Cité, Interfaces, Traitements, Organisation et Dynamique des Systèmes, UMR 7086, CNRS, Paris-Diderot University, 15 rue Jean de Baïf, F-75013 Paris, France. E-mail: roberta.brayner@univ-paris-diderot.fr

${ }^{c}$ Sorbonne Universités, UPMC Univ Paris 06, UMR 7588, Institut des Nanosciences de Paris, 4 place Jussieu, F-75005 Paris, France

${ }^{d}$ Institut Lavoisier de Versailles, 45 avenue des Etats-Unis, F-78035 Versailles, France

${ }^{e}$ Département RDDM, UMR 7245, Unité MCAM, Muséum National d'Histoire Naturelle, 57 rue Cuvier, F-75005 Paris, France

$\dagger$ Electronic supplementary information (ESI) available: Full experimental protocols for cell culture; gel time and optical density $v s$. silica concentration plots; macroscopic images of cell-containing gels: additional TEM images of pure and

cellularized hydrogels. See DOI: 10.1039/c7tb00341b
} 
cellular hosts as they can be prepared in aqueous media, at pH 7 and are self-forming (i.e. do not require any additional cross-linkers). ${ }^{13-15}$

A wide range of precursors, including gaseous, ${ }^{16}$ prehydrolyzed ${ }^{17}$ or water-soluble silicon alkoxides, ${ }^{18}$ silicates $^{19}$ and silica nanoparticles, ${ }^{20}$ have been used to design cytocompatible silica hydrogels. The latter silica sources have the advantage of being cheap and environmentally-benign. One possible approach relies on the acidification of aqueous sodium silicate solutions. ${ }^{21}$ This procedure is perfectly adapted to microorganisms able to cope with high salinity such as marine algae. ${ }^{22}$ However, for the majority of micro-organisms, a high sodium ion concentration can cause an osmotic shock and dehydration or at least a very significant stress during encapsulation. ${ }^{23}$ This issue has been successfully addressed by treating sodium silicate solutions with a cation-exchange resin resulting in a sodium-free precursor source,${ }^{24}$ but the fast gelation kinetics of these solutions do not allow forming gels with a high silica concentration. Alternatively, colloidal gels obtained from silica particles (Ludox ${ }^{\mathbb{R}}$ ) have been described ${ }^{20}$ but the absence of covalent interactions between these particles can lead to cellular hosts with low stability.

The possibility of obtaining more stable aqueous silica hydrogels at low ionic strength by using mixtures of sodium silicates and silica particles opened up new perspectives for cell encapsulation. ${ }^{25,26}$ It was found out that additives such as glycerol $^{27,28}$ or glycine betaine ${ }^{29}$ could improve the survival of cells encapsulated in these silica-in-silicates hosts. However, it was observed that small variations in the protocol could have a large impact on the hydrogel structure and therefore on its chemical and mechanical stability, as well as on its optical properties. ${ }^{30}$ While successful results have been recently obtained by substituting silicates with silicon alkoxides, ${ }^{31}$ most research in this area turned towards the design of (nano)biocomposite hosts, in which biological molecules such as phospholipids ${ }^{32,33}$ or polysaccharides $^{34,35}$ were used not only to provide a more cytocompatible environment to the cells but also as the template to control the internal structure and morphology of the hosts. Nanocomposites associating silica nanoparticles with organic polymers with promising mechanical properties were also described but their use for cell encapsulation was not reported so far. $^{36-38}$

Thus the silica-in-silicates nanocomposite hydrogels remain attractive materials for many applications where simplicity, low-cost and eco-compatibility of the process prevail over sophistication, ${ }^{39}$ for instance for in situ biosensing ${ }^{40}$ or bioremediation. ${ }^{41}$ However, this requires a detailed understanding of the relationships between the chemical conditions of synthesis (concentration of each precursors and $\mathrm{pH}$ ) and the mechanisms behind the formation of the hydrogels that dictate their physical properties (optical transparency and stiffness) and finally determine their impact on encapsulated cells. Here algal cells were selected as probes for the phycocompatibility of the process, not only because they usually allow for the evaluation in a wider range of $\mathrm{pH}$ and salinity than bacteria but also because immobilized photosynthetic organisms constitute the most popular type of cells currently studied for the design of environmental biosensors ${ }^{42,43}$ and green bioreactors. ${ }^{4,45}$

\section{Experimental}

\subsection{Silica hydrogel synthesis and characterization}

The preparation of silicate-in-silica hydrogels was performed following the protocol described by Coiffier et al. ${ }^{25}$ using a sodium silicate solution $\left(\mathrm{SiO}_{2} 27 \mathrm{wt} \%, \mathrm{NaOH} 10 \mathrm{wt} \%\right)$ and Ludox ${ }^{\circledR}$ HS40 colloids (12 nm in diameter, $40 \mathrm{wt} \%$ ). The sodium silicate solutions with concentrations ranging from $0.1 \mathrm{M}$ to $0.8 \mathrm{M}$ and Ludox solutions with concentrations ranging from $1 \mathrm{M}$ to $8 \mathrm{M}$ were obtained by dilution of the commercial sources in MilliQ water. Then $1 \mathrm{~mL}$ of each precursor was mixed under mild stirring, $1 \mathrm{~mL}$ of deionized water was added and $\mathrm{HCl} 4 \mathrm{M}$ was added to adjust the $\mathrm{pH}$ to 5,6 or 7 , i.e. neutral or slightly acidic conditions where microalgae were expected to survive. The delay between water addition and observation of a nonflowing system, as further checked by the tube inversion test, ${ }^{46}$ was considered as the gelation time, with a \pm 1 min estimated error. Additional experiments were performed using Ludox or silicate precursors only, in which case $1 \mathrm{~mL}$ of MilliQ water was used instead of silicate or Ludox solutions, respectively. In the following text, the gels will be identified by the final concentration of the precursors (i.e. 1/3 of the starting concentrations).

The optical properties of the gel were determined by measuring the absorbance at $\lambda=400 \mathrm{~nm}$ of gels directly formed in the cuvette. Since high absorbance values were obtained that may have caused saturation of the measurements, $0.5 \mathrm{~cm}$-thick cuvettes were used and the optical density $\mathrm{OD}_{400}$ was calculated as twice the measured value.

Transmission Electron Microscopy (TEM) was performed on a JEOL $100 \times$ using ultrathin sectioning of the gels after dehydration and embedding in an acrylate resin. Resulting images $(n=10)$ at various magnifications were analysed by image $\mathrm{J}$ the black \& white mode and taking the ratio between the white area and the total area as a measure of a (2D) porosity.

For mechanical tests, gel formation was performed in plastic containers allowing for easy recovery of the bulk hydrogels. Disk shaped samples had a diameter of $25 \mathrm{~mm}$ and a thickness of $10 \mathrm{~mm}$. Compression tests were performed using an ElectroForce 3200 Load Frame System (Bose) at a strain rate of $2.9 \% / \mathrm{s}$. No significant friction at the contact surface was observed ensuring uniform compression at small strains.

\subsection{Cell encapsulation and characterization}

Three different photosynthetic organisms were selected from the Museum National d'Histoire Naturelle collection to explore various physiological situations: the prokaryotic Anabaena flos-aquae (ALCP B24) cyanobacteria and two eukaryotic green algae, the Chlorellaceae Chlorella vulgaris (CCAP 211/11b) and the euglenozoa Euglena gracilis (ALCP 217). A. flos-aquae and C. vulgaris were grown in a Bold Basal medium at $\mathrm{pH} 7$ and E. gracilis in a Mineral medium at $\mathrm{pH}$ 3.6. Cells were cultivated for 3-4 weeks where they reached their mid log-phase, allowing 
us to recover a cell density of $10^{6}-10^{7}$ algae $\mathrm{mL}^{-1}$ (see ESI-1† for full description and growth curves). For encapsulation, the same protocol as for silica hydrogels was used except that $1 \mathrm{~mL}$ of the cell suspension was mixed with the silica precursors instead of deionized water before adjusting the $\mathrm{pH}$.

The influence of the $\mathrm{pH}$, silicate and Ludox concentrations on cell activity was studied by measuring the fluorescence of chlorophyll a $\left(\lambda_{\text {exc }}=470 \mathrm{~nm} ; \lambda_{\mathrm{em}}=680 \mathrm{~nm}\right), 1$ day and 15 days after encapsulation. The effect of $\mathrm{pH}$ variation was also monitored for cell suspensions.

Encapsulated cells were observed using TEM, following the above-described procedure except for additional staining with uranyl acetate and lead citrate, and using Scanning Electron Microscopy using a ZEISS microscope equipped with a Field Gun (SEM-FEG) after fixation, dehydration and supercritical drying of the samples.

\section{Results}

\subsection{Silicates and Ludox behavior}

In a first step, the behavior of silicates and Ludox solutions alone was studied. For Ludox solutions, no gel was observed after $24 \mathrm{~h}$, whatever the $\mathrm{pH}$ between 5 and 7 or the concentration in a [Ludox] $=0.33-2.66 \mathrm{M}$ range. The optical density at $400 \mathrm{~nm}, \mathrm{OD}_{400}$, was similar for all solutions at 0.33 M (Fig. 1(a)). At $\mathrm{pH} 7, \mathrm{OD}_{400}$ slightly increased with increasing particle concentration. A similar evolution was obtained at $\mathrm{pH} 6$ up to [Ludox] $=2.33 \mathrm{M}$ and then $\mathrm{OD}_{400}$ increased sharply. At $\mathrm{pH}$ $5 \mathrm{OD}_{400}$ values systematically increased with particle content. The OD increase observed at a low $\mathrm{pH}$ and/or a high Ludox content is in agreement with the enhanced tendency of the nanoparticles to aggregate when their surface charge is lowered and/or concentration is increased.

For silicates, no gel was obtained at $\mathrm{pH} 5$ nor at [silicate] = $0.03 \mathrm{M}$ at pH 6 and 7. At [silicate] $=0.06 \mathrm{M}$ and above, gelation occurred and the gel time decreased with increasing silicate concentration (Fig. 1(b)). At pH 6, the decay in the gel time was fast between [silicate] $=0.06 \mathrm{M}$ and $0.13 \mathrm{M}$ and then becomes slow. At $\mathrm{pH} \mathrm{7,} \mathrm{this} \mathrm{trend} \mathrm{was} \mathrm{shifted} \mathrm{to} \mathrm{a} \mathrm{lower} \mathrm{silica} \mathrm{concen-}$ tration and shorter gel times were obtained compared to $\mathrm{pH} 6$,
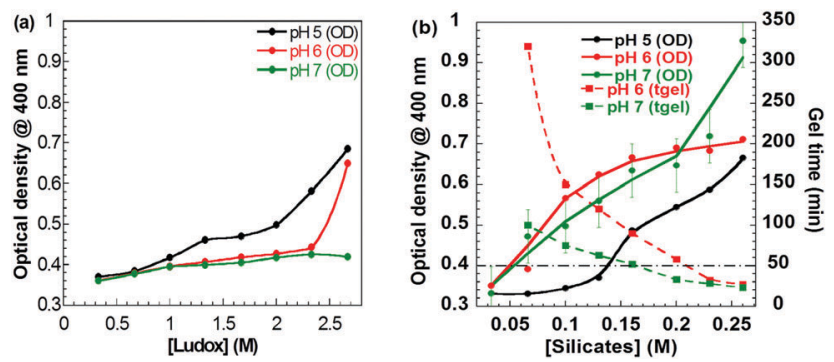

Fig. 1 Evolution of (a) optical density at $400 \mathrm{~nm}$ with Ludox concentration and (b) optical density at $400 \mathrm{~nm}$ (plain line) and gel time (dashed line) with silicate concentration at $\mathrm{pH} 5-7$. Horizontal line provides a guideline to the eye to illustrate the influence of $\mathrm{pH}$. Note that neither Ludox solutions nor silicate solutions undergo gelation at $\mathrm{pH} 5$ under the conditions of this study. i.e. a similar gel time of $c a$. $50 \mathrm{~min}$ was obtained for [silicate] = $0.2 \mathrm{M}$ at $\mathrm{pH} 6$ and [silicate] $=0.16 \mathrm{M}$ at $\mathrm{pH}$ 7. As far as absorbance is concerned, the $\mathrm{OD}_{400}$ value at [silicate] = $0.03 \mathrm{M}$ is $c a$. 0.35 , independently of $\mathrm{pH}$. At $\mathrm{pH} 5$, this value increased slowly at a low silicate concentration and then more rapidly. At $\mathrm{pH} 6$, the $\mathrm{OD}_{400}$ values increased rapidly and regularly with silicate content and then more slowly. The final $\mathrm{OD}_{400}$ is close to that of the $\mathrm{pH} 5$ sample at the same concentration. At $\mathrm{pH} 7$, the $\mathrm{OD}_{400}$ increase is almost similar to $\mathrm{pH} 6$, except for the final steeper increase. Noticeably, the optical properties of the gel, indicative of the structure of the silica network, are similar at $\mathrm{pH} 6$ and $\mathrm{pH} 7$ at low concentrations and at pH 5 and 6 at high concentrations but, in both cases, different gelation kinetics are observed, suggesting that the strength of the inter-particle interactions is a key factor determining the gelation kinetics.

\subsection{Kinetics of nanocomposite hydrogel formation}

Silicate-Ludox mixed systems were then investigated at various concentrations and $\mathrm{pHs}$ 5-7. As a general trend, for a given composition, the gelation time is the shortest at $\mathrm{pH} 7$ and the longest at $\mathrm{pH} 5$, while values obtained at $\mathrm{pH} 6$ are slightly smaller or similar to those obtained at pH 5 (Fig. 2a-c). At pH 7, the gelation time decreases rapidly with increasing silicate concentration and then reaches a plateau. At pH 6, the decrease step is more progressive whereas $\mathrm{pH} 5$ represents an intermediate situation. Data plotted as a function of total $\left[\mathrm{SiO}_{2}\right]$ concentration evidence that the gel time is more sensitive to variations in the silicate concentration than in the Ludox content (ESI- $\dagger$ ). It is thus possible to obtain gels having similar gelation kinetics at almost all Ludox concentrations for a given $\mathrm{pH}$ whereas equivalent gel times cannot be obtained at all silicate concentrations at pH 5 and 6 .

\subsection{Optical properties of the nanocomposite hydrogels}

Considering gel absorbance, evolution with a silicate concentration and a Ludox content is very similar at pH 5 and $\mathrm{pH} 6$ (Fig. 2e and f). $\mathrm{OD}_{400}$ increases with increasing amount of both species, reaches a plateau and decreases at high Ludox and silicate concentrations. At $\mathrm{pH} 7$, a similar trend is found at low and intermediate silica concentrations although the $\mathrm{OD}_{400}$ values are smaller than for more acidic conditions (Fig. 2d). However, at high Ludox and silicate concentrations, the absorbance increases significantly. When considering the variations with total silica content, the absorbance is again more sensitive to variations in the silicate content than in Ludox, with gels of similar $\mathrm{OD}_{400}$ being obtained at almost all Ludox concentrations for a given $\mathrm{pH}(\mathrm{ESI}-2 \dagger)$. However, it is also possible to synthesize gels with similar absorbance at almost all silicate concentrations. These curves also enlighten the peculiar effect of high concentrations of silicates that decrease the gel absorbance under most conditions.

\subsection{Structural properties of the nanocomposite hydrogels}

Selected samples were also examined by TEM (Fig. 3 and ESI- $3 \dagger$ ) and the apparent porosity (in $\%$ of the surface, $\pm 2 \%$ ) was 

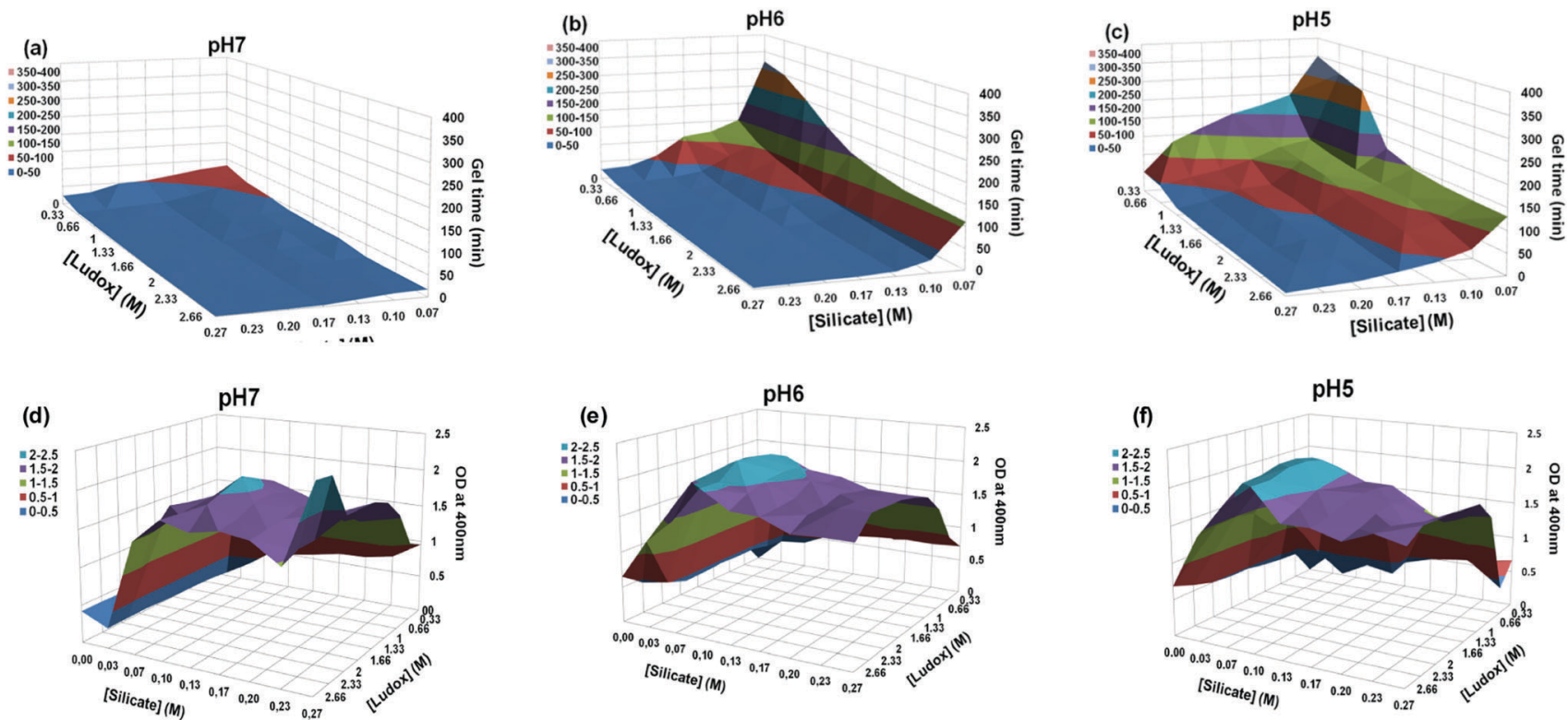

Fig. 2 Evolution of $(a-c)$ the gelation time and (d-f) optical density at $400 \mathrm{~nm}$ with silicate and Ludox concentrations at pH 7 (a and d), pH 6 (b and e) and $\mathrm{pH} 5$ ( $\mathrm{c}$ and f). Colors indicate $(\mathrm{a}-\mathrm{c}$ ) the range of gelation time (in $\mathrm{min}$ ) and (d-f) the range of optical density at $400 \mathrm{~nm}$, with corresponding values being indicated on the left-hand side of each plot.
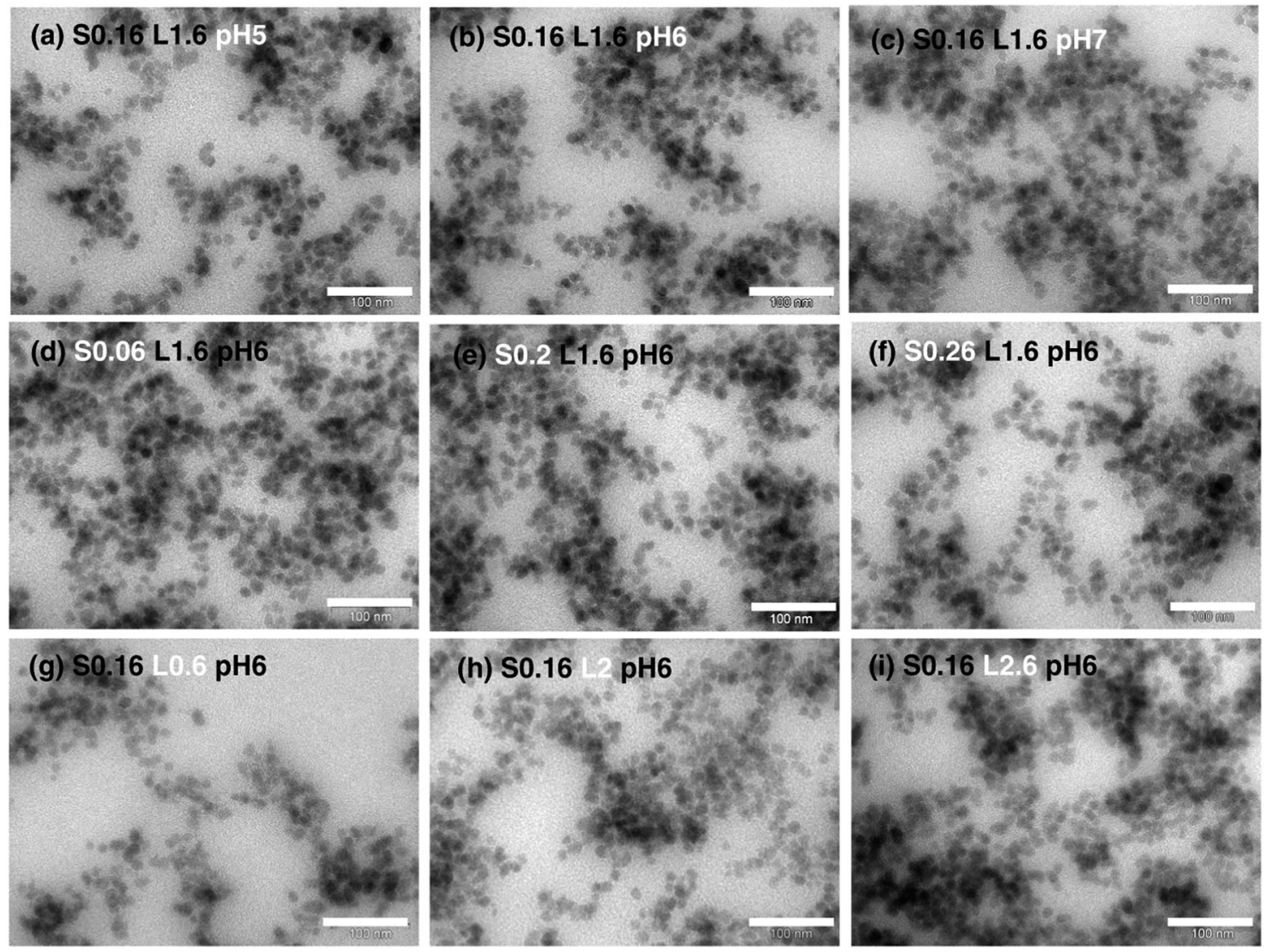

Fig. 3 TEM images of gels $(a-c)$ at fixed silicate and Ludox and variable $\mathrm{pH},(\mathrm{d}-\mathrm{f})$ at fixed Ludox and $\mathrm{pH}$ and variable silicate, ( $\mathrm{g}-\mathrm{i})$ at fixed silicate and $\mathrm{pH}$ and variable Ludox (scale bar $=100 \mathrm{~nm}$ ). $\mathrm{S}=$ silicate concentration (in $\mathrm{M}$ ); $\mathrm{L}=$ Ludox concentration (in $\mathrm{M}$ ).

evaluated using Image $\mathrm{J}$. Whereas $\mathrm{pH}$ variations for fixed silicate $(0.16 \mathrm{M})$ and Ludox $(1.66 \mathrm{M})$ did not impact significantly the structure of the network (apparent porosity $c a .60 \%$ ), the increase of the silicate concentration from $0.06 \mathrm{M}$ to $0.26 \mathrm{M}$ at 
a fixed Ludox content (1.66 M) and pH (6) slightly increased the apparent porosity from $55 \%$ to $60 \%$. The most significant variations were obtained when increasing the Ludox content from $0.66 \mathrm{M}$ to $2.66 \mathrm{M}$ (at fixed silicate $(0.16 \mathrm{M}$ ) and $\mathrm{pH}(6))$ with a decrease in apparent porosity from $78 \%$ to $50 \%$. To understand these variations, it must be considered that colloidal gels are formed by the connection of particles and their porosity corresponds to the inter-particle voids. It can decrease if the number of particles increases, as observed here for increasing Ludox concentration. Alternatively, it can vary with the size of the particles. TEM images suggest that in the nanocomposite system these particles mainly correspond to aggregates of the Ludox nanoparticles. Hence, it can be suggested that in the presence of silicates, $\mathrm{pH}$ variation has little if any effect on Ludox aggregation whereas silicate condensation has a strong influence on this process.

\subsection{Mechanical properties of the nanocomposite hydrogels}

Selected gels were evaluated by compression tests. Some representative curves and summarizing plots are gathered in Fig. 4 . For silicate-only gels, the stress-strain curves show a rapid increase followed by a plateau or even a decrease corresponding to the gel crushing (Fig. 4a). The Young's modulus $E$, as calculated from the slope of the initial linear part of the curve, slightly increased with silicate concentration. The introduction of Ludox at an intermediate concentration $(1.66 \mathrm{M})$ significantly increases the $E$ values (Fig. 4b). Overall, when $E$ is plotted as a function of total silica concentration, a continuous increase of the Young's modulus is observed with similar values being obtained at all pHs (Fig. 4c). Noticeably, above $1 \mathrm{M}$ of total silica, the log-log scale plot is linear, indicating a power-law relationship between the silica concentration and $E$.

\subsection{Influence of encapsulation on cell activity}

Reference conditions for gel formation were selected in the middle range of explored systems, i.e. [silicate] $=0.16 \mathrm{M}$, [Ludox] = $1.6 \mathrm{M}$ and $\mathrm{pH} 6$, and these different parameters were varied keeping the two others constant.

In a first step, the effect of $\mathrm{pH}$ variation was studied for both cell suspensions and encapsulated cells (Fig. 5). For A. flosaquae, the fluorescence signal dramatically fell down to zero after 15 days of exposure to $\mathrm{pH} 5$, while no effect was observed at pH 6 and 7 (Fig. 5a). This effect was confirmed by macroscopic observations of the gels (ESI- $4 \dagger$ ), showing strong discoloration of the cell suspension at this $\mathrm{pH}$. After encapsulation, the fluorescence level under acidic conditions remained comparable to that of other $\mathrm{pH}$ conditions even after 15 days of contact (Fig. 5d). A similar observation was made for $C$. vulgaris where the high sensitivity of this alga to acidic conditions in suspension, even after 1 day, (Fig. 5b and ESI- $4 \dagger$ ) was also compensated by the encapsulation process (Fig. 5e). In sharp contrast, E. gracilis showed no specific response to $\mathrm{pH}$ conditions, whether in suspension or within the gels (Fig. $5 \mathrm{c}$ and $\mathrm{f}$ ).

The effect of Ludox and silicate concentrations on encapsulated cells was then investigated. A. flos-aquae showed a strong sensitivity to Ludox concentrations larger than $1.6 \mathrm{M}$, especially
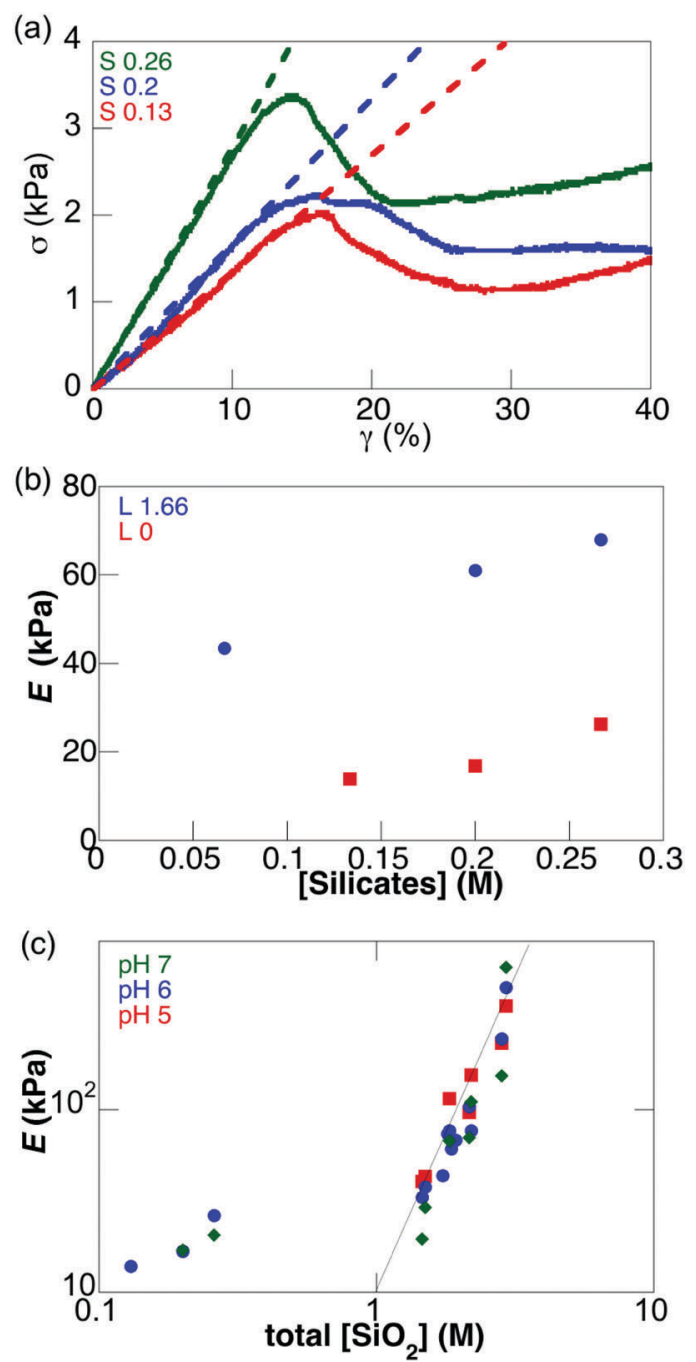

Fig. 4 (a) Strain-stress curves of gels prepared from silicate alone solutions at $\mathrm{pH} 6$, (b) variation of the Young's modulus $E$ of gels obtained at two Ludox concentrations as a function of silicate concentration at $\mathrm{pH} 6$, (c) variation of the Young's modulus $E$ with total $\mathrm{SiO}_{2}$ concentration at three $\mathrm{pHs}$ on a log-log scale. The dotted line indicates a power-law relationship between $\left[\mathrm{SiO}_{2}\right]$ and $E$. $S$ = silicate concentration (in $\mathrm{M}$ ); $\mathrm{L}=$ Ludox concentration (in M).

after 15 days, whereas $C$. vulgaris and E. gracilis showed more limited loss of fluorescence over the same period (Fig. 6a-c). In contrast, all cells were highly sensitive to increasing concentrations of silicates after 1 day but the fluorescence intensity did not significantly evolve during the next two weeks (Fig. 6d-f).

\subsection{Influence of encapsulation on the cell structure}

Cells encapsulated in the reference gel were observed by SEM (Fig. 7). The filamentous A. flos-aquae is easily imaged, evidencing that part of the organism is buried within the silica network. C. vulgaris and E. gracilis are also surrounded by the inorganic material. No apparent degradation of the cell wall could be evidenced and it was even possible to image the flagella of E. gracilis. TEM confirms the preservation of the ultrastructure of the algae (Fig. 7). For A. flos-aquae and C. vulgaris, the cells are 

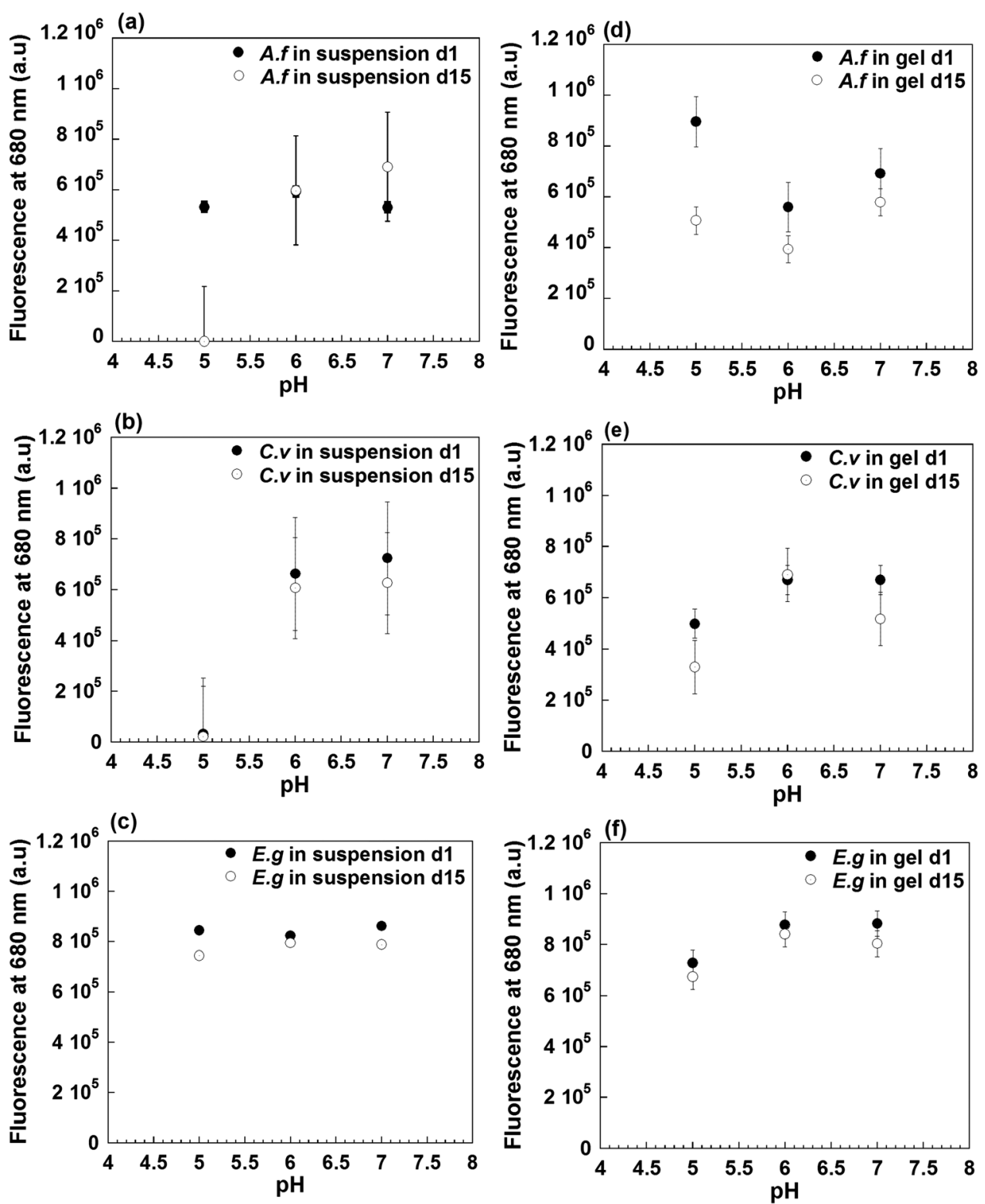

Fig. 5 Effect of pH on chlorophyll a fluorescence for (a and d) A. flos-aquae (A. f.), (b and e) C. vulgaris (C. v.) and (c and f) E. gracilis (E. g.) in suspension $(a-c)$ and within reference silica gels $(d-f)$.

surrounded by a cavity but contact points between the silica network and the cell walls can be observed. In contrast such a cavity is not present for E. gracilis.

The impact of a more acidic $\mathrm{pH}$ and of a higher silicate concentration on the encapsulated cell ultrastructure was also studied (ESI-5 $\dagger$ ). Cells encapsulated in hydrogels prepared at $\mathrm{pH} 5$ showed a good preservation of the ultrastructure but an additional dense polysaccharide network was observed at the cell surface. In contrast, TEM images of A. flos-aquae immobilized in matrices obtained at a $0.26 \mathrm{M}$ silicate concentration showed an apparently empty cellular envelope with a wide aperture, suggesting that cell lysis has occurred, and covered by a thick coating. In the case of $C$. vulgaris at a similar silicate concentration, a similar lysis and intracellular component leaching is observed but the remaining membrane contains a granular material that is highly reminiscent of the surrounding silica network, suggesting that some Ludox particles have penetrated inside the cell. For E. gracilis, penetration of silica within the cell is also evidenced although its point of entry within the cytoplasm is difficult to distinguish.

\section{Discussion}

Silicates-in-silica nanocomposite hydrogels were introduced by Coiffier et al. as solvent-free alternatives to silicon alkoxidebased gels for cell encapsulation. ${ }^{25}$ They were initially developed for the immobilization of bacteria that, in a wide majority, survive only under near neutral $\mathrm{pH}$ conditions and at a moderate ionic strength. ${ }^{26,27}$ This led to the identification of 

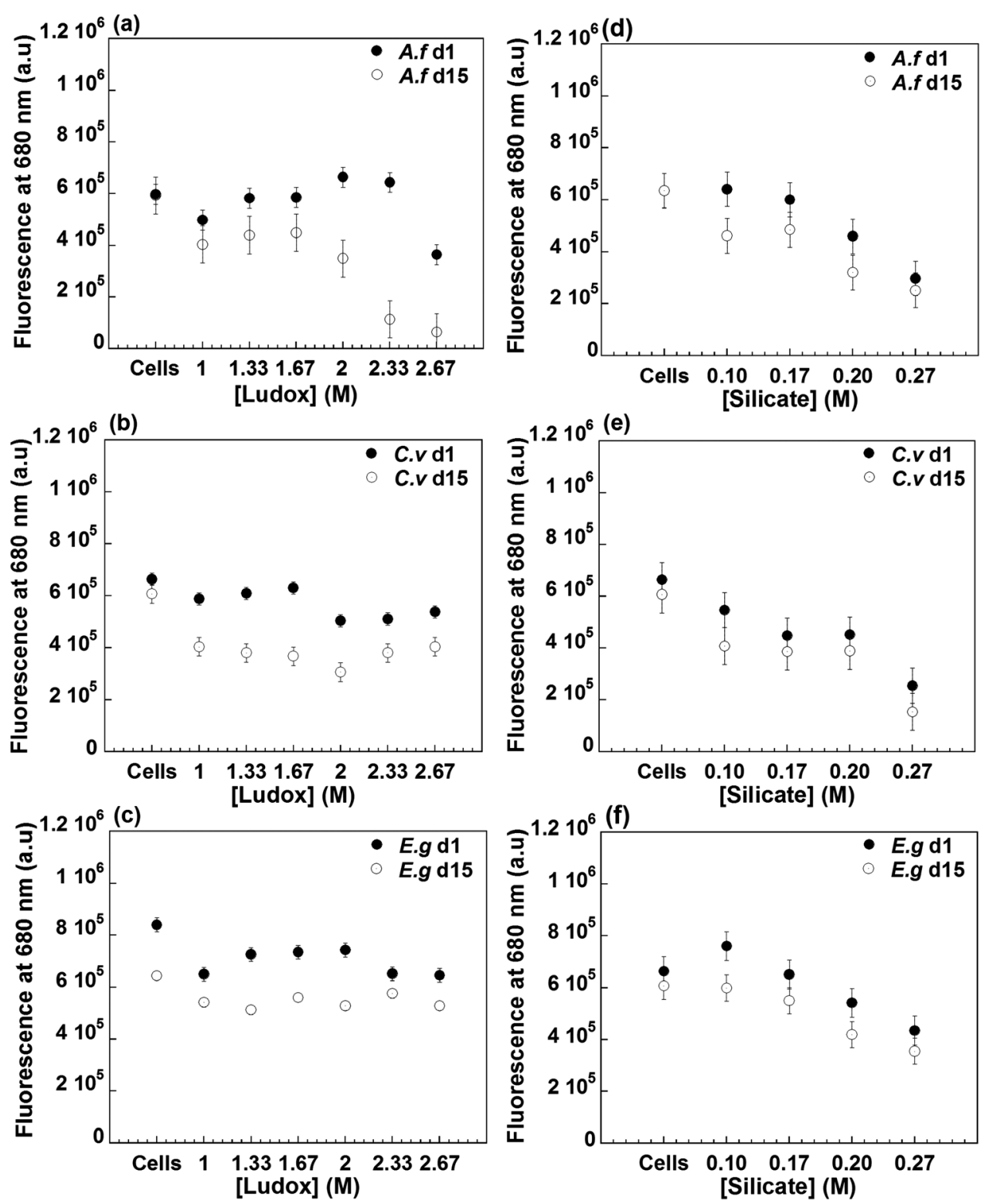

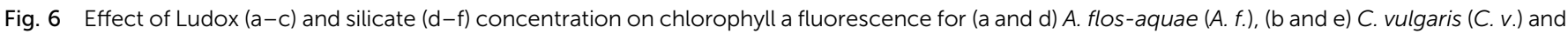
(c and f) E. gracilis (E. g.) within reference silica gels (d-f).

a narrow range of conditions, in terms of silicate and Ludox concentrations as well as $\mathrm{pH}$ conditions, compatible with the survival of bacteria. In order to improve the optical properties and mechanical stability of these hosts, extension of the precursor concentration range was proposed but it required the addition of cell-protective agents. ${ }^{23}$ However, if the encapsulation of more robust organisms, such as algal cells, is targeted, it should be possible to extend the conditions of preparation, and therefore the range of properties, of these nanocomposites while preserving their cytocompatibility.

The here-presented screening of the concentration and $\mathrm{pH}$ conditions evidences that among the two precursors, silicates play the most prominent role in the kinetics of gel formation, even though it is introduced at concentrations $c a .10$ times lower than Ludox. In this context, a decrease in the gel time with increasing Ludox concentration should reflect the fact that these particles occupy an increasing volume fraction of the solution. This decreases the water volume fraction that needs to be filled by silicate condensation to achieve the formation of a percolated network.

The evolution of the optical properties of the nanocomposites also follows a similar trend to that of pure silicate solutions except for two noticeable points. First, the $\mathrm{OD}_{400}$ values of the composites are significantly higher than silicates alone, indicating that Ludox nanoparticles contribute to the diffusion behavior of the composite. Second, at a high Ludox concentration, the $\mathrm{OD}_{400}$ value of the nanocomposites decreases, suggesting that some interactions exist between silicates and colloidal silica.

In contrast to aerogels ${ }^{47}$ or hybrid materials, ${ }^{48}$ the mechanical behavior of wet silica gels has been sparingly studied so far. 

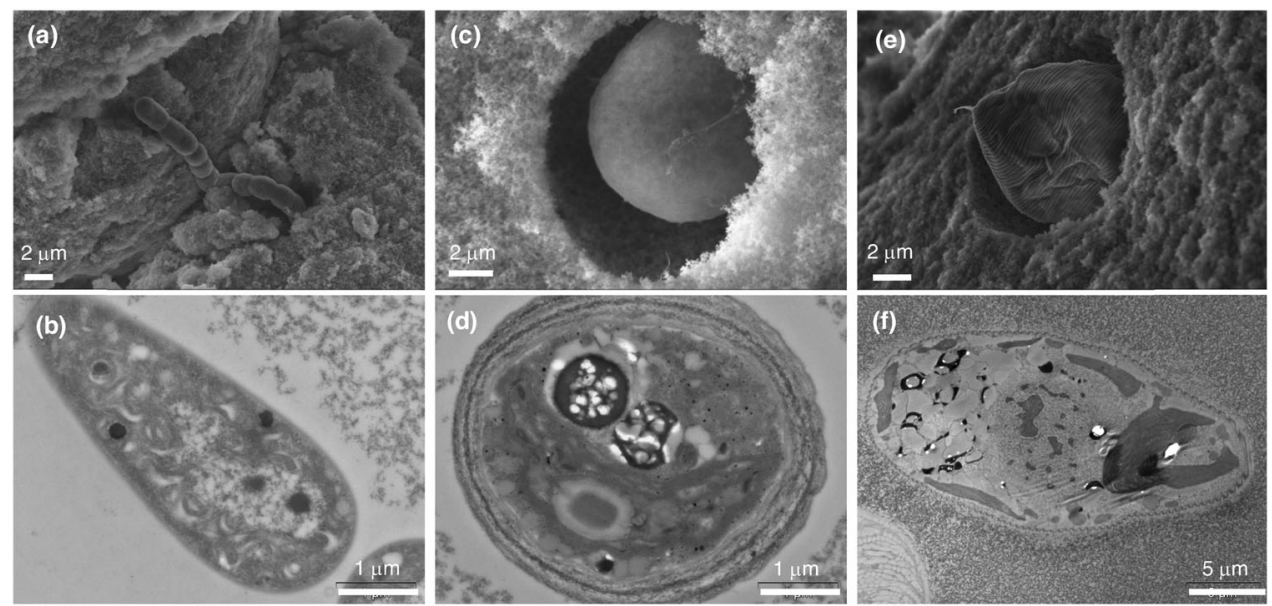

Fig. 7 SEM and TEM images of (a and b) A. flos-aquae, (c and d) C. vulgaris and (e and f) E. gracilis encapsulated in the reference gel (pH 6).

While several rheological studies of alkoxide-, ${ }^{49,50}$ nanoparticle- $^{51,52}$ and silicate-based ${ }^{53-55}$ gels have been described, compression tests performed on silica hydrogels are scarce. ${ }^{56-59}$ For Ludox-only systems, it was suggested that colloidal gels consist of particle clusters that interact one with another. ${ }^{60,61}$ Such a structure is clearly visible on the TEM images of our materials that appear formed via the connection of Ludox aggregates. The behavior under strain of colloidal gels depends on the relative elastic strength of the intracluster $v s$. intercluster interactions, which varies with particle concentration and interparticle interactions. ${ }^{51}$ Here a major difference is that our system consists of a reticulated silicate matrix that can link particle aggregates together. A major consequence is that nanocomposites can be obtained for Ludox solutions that do not form gels on their own. Nevertheless, the evidence for a power-law relationship between the Young's modulus and total $\mathrm{SiO}_{2}$ indicates that the nanocomposite system still behaves as a colloidal gel. ${ }^{62}$ This suggests that the major role of the silicates is to fill the liquid phase between Ludox aggregates via condensation, allowing to reach percolation. Nevertheless, both optical and TEM data indicate that silicate-colloid interactions can influence the nanocomposite structure when the soluble precursor is present at a high concentration. In addition to the above-mentioned modification of the Ludox aggregate size, such interactions should decrease the amount of polymerizing species available in the solution, opening the matrix structure.

Noticeably, previous reports on silicate:Ludox hydrogels showed that, at a fixed total silica concentration (2.1 M), the Young's modulus slightly decreases as the relative amount of Ludox increases, which was correlated with the increase in the porous volume. $^{23}$ The mechanical properties of tetraethoxysilane:Ludox (HS40) silica hydrogels were also reported, ${ }^{58}$ showing that the mechanical stability of the gel increased with increasing alkoxide content at constant particle concentration. Using larger particles, for a given total silica concentration, the elastic modulus of the gel decreased with increasing particle size. The latter observation is in agreement with our hypothesis that the particle aggregate size and cohesion play a major role in the compression behavior of the hydrogels.
Considering the impact of the encapsulation on cell viability, it is first worth pointing out that the measured effect of $\mathrm{pH}$ variations on cell suspension is in agreement with their physiological characteristics. Prokaryotic photosynthetic organisms, such as A. flos-aquae, are usually considered to be more sensitive to several external parameters, being chemical or mechanical, than eukaryotic ones. ${ }^{63}$ In contrast, E. gracilis are particularly robust organisms, thanks to their physiological features that make them phylogenetically close to protozoa such as Leshmania. ${ }^{64}$ Finally most eukaryotic micro-algae, such as C. vulgaris, are sensitive to acidic pHs. ${ }^{65}$ The improvement of A. flos-aquae and C. vulgaris viability under acidic conditions after encapsulation is to be linked with numerous reports of higher $\mathrm{pH}$ stability of silica-encapsulated biological samples. ${ }^{66}$ Among possible effects, the buffering capacity of silanol groups present on the surface of internal pores appears to be particularly relevant. ${ }^{67,68}$ In addition, we have observed a thick polysaccharide coating on these two cells encapsulated at $\mathrm{pH}$, which can also trap protons and avoid their diffusion to the cytoplasm.

The two eukaryotic organisms were not significantly impacted by high Ludox concentrations whereas the prokaryotic $A$. flos-aquae was highly sensitive to these. If we correlate these observations with the properties of the corresponding matrices, it is to be noticed that they all exhibit similar gel times and optical properties. In contrast, their Young's modulus increases by a factor of 10 when the Ludox concentration increases from $1 \mathrm{M}$ to $3 \mathrm{M}$. Such a relationship between the mechanical properties and $A$. flos-aquae survival is in good agreement with the fact that this effect is particularly evidenced 15 days after encapsulation, i.e. after gel strengthening via syneresis. ${ }^{53}$

Finally, the increase of the sodium silicate concentration was detrimental to the three cells. However, in the investigated range of conditions, neither the optical nor the mechanical properties of the matrices were significantly modified by the silicate concentration. In contrast, the gel time did vary between $2 \mathrm{~h}$ and a few minutes. It is usually considered that too short gelation times are not favorable to cell survival since they do not allow their adaptation to their new environments. In parallel, too long gelation times can also be detrimental as 
they allow for an extended contact time between the cells and the precursors, which may be cytotoxic. Whereas it is difficult to conclude on this point, the increase in ionic strength with silicate concentration constitutes a more straightforward explanation for our observation. Indeed, intracellular osmotic pressure can be efficiently regulated by cells and several mechanisms exist to compensate for a limited increase of the external ionic strength. However, above a certain value, the cell membrane can no longer control the ionic equilibria nor resist to the induced pressure difference, resulting in cell lysis, as observed here by TEM.

Altogether, it is possible to define conditions that are compatible with the survival of the three studied organisms over 2 weeks: (i) the pH 5-7 range is acceptable for all encapsulated cells, (ii) Ludox concentrations up to $1.66 \mathrm{M}$ are suitable for all organisms but higher contents can be used for the eukaryotic cells, (iii) the most stringent condition is related to the silicate concentration that should remain below $0.16 \mathrm{M}$. Under these conditions, it is nevertheless possible to vary both the absorbance at $400 \mathrm{~nm}$ and the Young's modulus (for eukaryotic cells) by a factor of 10, offering a large diversity of encapsulation hosts.

\section{Conclusions}

Varying the precursor concentrations and $\mathrm{pH}$ conditions in the preparation of silica-in-silicates nanocomposite hydrogels offers the possibility of obtaining a wide variety of materials with a tunable gel time, transparency and mechanical properties. Underlying chemical and structuration processes revealed to be more complex than expected, especially at high contents of both molecular and colloidal sources. Among the available experimental conditions, only some of them are suitable for microalgae encapsulation, in a highly speciesspecific manner. In particular the ionic strength and mechanical constraint appear to be the key factors determining cell viability whereas the detrimental effect of acidic conditions can be suppressed by encapsulation. Based on this, it is now possible to define the optimal conditions for encapsulation of a given organism based on its physiological features. This provides a unique opportunity for the full integration of microbial biodiversity within functional devices such as environmental biosensors and bioreactors.

\section{Acknowledgements}

N. B. PhD was funded by the French Ministry for Superior Education and Research. We acknowledge the ImagoSeine facility (Jacques Monod Institute, Paris, France), and the France BioImaging infrastructure supported by the French National Research Agency (ANR-10-INSB-04, "Investments fit the future"). The authors thank A. Couté (MNHN) and M. Perullini (Univ. Buenos Aires-CONICET) for fruitful discussions.

\section{References}

1 S. J. Hollister, Nat. Mater., 2005, 4, 518.

2 Y. Kourkouta, A. Bekatorou, I. M. Banat, R. Marchant and A. A. Koutinas, Food Microbiol., 2004, 21, 377.
3 N. Licata, B. Mohari, C. Fuqua and S. Setayesgar, Biophys. J., 2016, 110, 247.

$4 \mathrm{~J}$. Zeltinger, J. K. Sherwood, D. A. Graham, R. Müller and L. G. Griffith, Tissue Eng., 2004, 7, 557.

5 B. J. Lawrence and S. V. Madihally, Cell Adhes. Migr., 2008, 2, 9.

6 J. J. Pancrazio, J. P. Whelan, D. A. Borkholder, W. Ma and D. A. Stenger, Ann. Biomed. Eng., 1999, 27, 697.

7 H. C. Greenwell, L. M. L. Laurens, R. J. Shields, R. W. Lovitt and K. J. Flynn, J. R. Soc., Interface, 2010, 7, 703.

8 F. J. O'Brien, Mater. Today, 2011, 14, 88.

9 G. D. Nicodemus and S. J. Bryant, Tissue Eng., Part B, 2008, 14, 149.

10 I. Gill and A. Ballesteros, Trends Biotechnol., 2000, 18, 469.

11 N. Reddy, R. Reddy and Q. Jiang, Trends Biotechnol., 2015, 33, 362 .

12 S. R. Caliari and J. A. Burdick, Nat. Methods, 2016, 13, 405.

13 M. Blondeau and T. Coradin, J. Mater. Chem., 2012, 22, 22335.

14 R. Ciriminna, M. Sciortino, G. Alonzo, A. de Schrijver and M. Pagliaro, Chem. Rev., 2011, 111, 765.

15 R. Ciriminna, A. Fidalgo, V. Pandarus, F. Béland, L. M. Ilharco and M. Pagliaro, Chem. Rev., 2013, 113, 6592.

16 G. Carturan, R. Dal Toso, S. Boninsegna and R. Dal Monte, J. Mater. Chem., 2004, 14, 2087.

17 H. Böttcher, U. Soltmann, M. Mertig and W. Pompe, J. Mater. Chem., 2004, 14, 2176.

18 P. N. Catalano, N. S. Bourguignon, G. S. Alvarez, C. Libertun, L. E. Diaz, M. F. Desimone and V. Lux-Lantos, J. Mater. Chem., 2012, 22, 11681.

19 C. Sicard, R. Brayner, J. Margueritat, M. Hémadi, A. Couté, C. Yéprémian, C. Djediat, J. Aubard, F. Fiévet, J. Livage and T. Coradin, J. Mater. Chem., 2010, 20, 9342.

20 K. S. Finnie, J. R. Bartlett and J. L. Woolfrey, J. Mater. Chem., 2000, 10, 1099.

21 R. B. Bhatia and C. J. Brinker, Chem. Mater., 2000, 12, 2434.

22 C. Gautier, T. Coradin and P. J. Lopez, Chem. Commun., 2006, 4611.

23 M. Perullini, M. Amoura, C. Roux, T. Coradin, J. Livage, M. L. Japas, M. Jobbagy and S. A. Bilmes, J. Mater. Chem., 2011, 21, 4546.

24 D. Yu, J. Volponi, S. Chhabra, C. J. Brinker, A. Mulchandani and A. K. Singh, Biosens. Bioelectron., 2005, 20, 1433.

25 A. Coiffier, T. Coradin, C. Roux, O. M. M. Bouvet and J. Livage, J. Mater. Chem., 2001, 11, 2039.

26 N. Nassif, O. Bouvet, M. N. Rager, C. Roux, T. Coradin and J. Livage, Nat. Mater., 2002, 1, 42.

27 N. Nassif, C. Roux, T. Coradin, M.-N. Rager, O. M. M. Bouvet and J. Livage, J. Mater. Chem., 2003, 13, 203.

28 N. M Eleftheriou, X. Ge, J. Kolesnik, S. B. Falconer, R. J. Harris, C. Khursigara, E. D. Brown and J. D. Brennan, Chem. Mater., 2013, 25, 4798.

29 T. J. Savage, D. R. Dunphy, S. Harbaugh, N. KelleyLoughnane, J. C. Harpera and C. J. Brinker, ACS Biomater. Sci. Eng., 2016, 1, 1231.

30 M. Perullini, N. Levinson, M. Jobbagy and S. A. Bilmes, J. Sol-Gel Sci. Technol., 2016, 77, 437. 
31 B. R. Mutlu, S. Yeom, H. W. Tong, L. P. Wackett and A. Aksan, J. Mater. Chem. A, 2013, 1, 11051.

32 J. C. Harper, C. Y. Khripin, E. C. Carnes, C. E. Ashley, D. M. Lopez, T. Savage, H. D. Jones, R. W. Davis, D. E. Nunez and C. J. Brinker, ACS Nano, 2010, 4, 5539.

33 P. E. Johnson, P. Muttil, D. MacKenzie, E. C. Carnes, J. Pelowitz, N. A. Mara, W. M. Mook, S. D. Jett, D. R. Dunphy, G. S. Timmins and C. J. Brinker, ACS Nano, 2015, 9, 6961.

34 A. Pannier, U. Soltmann, B. Soltmann, R. Altenburger and M. Schmitt-Jansen, J. Mater. Chem. B, 2014, 2, 7896.

35 J. Desmet, C. F. Meunier, E. P. Danloy, M. E. Duprez, A. L. Hantson, D. Thomas, P. Cambier, J. C. Rooke and B. L. Su, J. Mater. Chem. A, 2014, 2, 20560.

36 L. Carlsson, S. Rose, D. Hourdet and A. Marcellan, Soft Matter, 2010, 3, 3619.

37 W.-C. Lin, A. Marcellan, D. Hourdet and C. Creton, Soft Matter, 2011, 7, 6578.

38 J. Yang, C.-R. Han, J.-F. Duan, F. Xu and R.-C. Sun, Nanoscale, 2013, 5, 10858.

39 N. Baccile, F. Babonneau, B. Thomas and T. Coradin, J. Mater. Chem., 2009, 19, 8537.

40 E. Michelini, L. Cevenini, M. M. Calabretta, S. Spinozzi, C. Camborata and A. Roda, Anal. Bioanal. Chem., 2013, 405, 6155 .

41 B. R. Mutlu, S. Yeom, L. P. Wackett and A. Aksan, Chem. Eng. J., 2015, 259, 574.

42 C. Durrieu, H. Guedri, F. Fremion and L. Volatier, Res. Microbiol., 2011, 162, 908.

43 R. Brayner, A. Couté, J. Livage, C. Perrette and C. Sicard, Anal. Bioanal. Chem., 2011, 401, 581.

44 J. C. Rooke, A. Leonard, C. F. Meunier and B. L. Su, ChemSusChem, 2011, 4, 1249.

45 D. J. Dickson and R. L. Ely, Appl. Microbiol. Biotechnol., 2013, 97, 1809.

46 S. R. Raghavan and B. H. Cipriano, in Molecular gels, ed. R. G. Weiss and P. Terech, Springer, 2006, vol. 8, pp. 241-252.

47 T. Woignier, J. Primera, A. Alaoui, P. Etienne, F. Despestis and S. Calas-Etienne, Gels, 2015, 1, 256.
48 F. Mammeri, E. Le Bourhis, L. Rozes and C. Sanchez, J. Mater. Chem., 2005, 15, 3787.

49 M. D. Sacks and R.-S. Sheu, J. Non-Cryst. Solids, 1987, 92, 383.

50 A. Ponton, S. Warlus and P. Griesmar, J. Colloid Interface Sci., 2002, 249, 209.

51 X. J. Cao, H. Z. Cummins and J. F. Morris, Soft Matter, 2010, 6, 5425 .

52 C. O. Metin, K. M. Rankin and Q. P. Nguyen, Appl. Nanosci., 2014, 4, 93.

53 C. Gautier, A. Ponton, J. Livage, P. J. Lopez and T. Coradin, J. Sol-Gel Sci. Technol., 2009, 50, 164.

54 A. Kaide and T. Saeki, Nihon Reoroji Gakkaishi, 2012, 40, 165.

55 M. Wang, H. H. Winter and G. K. Auernhammer, J. Colloid Interface Sci., 2014, 413, 159.

56 A. Han, V. K. Punyamurthula, W. Lu and Y. Qiao, J. Appl. Phys., 2008, 103, 084318.

57 I. Krupa, T. Nedelcev, D. Racko and I. Lacik, J. Sol-Gel Sci. Technol., 2010, 53, 107.

58 B. R. Mutlu, S. Yeom, H.-W. Tong, L. P. Wackett and A. Aksan, J. Mater. Chem. A, 2013, 1, 11051.

59 W. H. Shih, J. Liu, W. Y. Shih, M. Sarikaya and I. A. Aksay, Mater. Res. Soc. Symp. Proc., 1989, 155, 83.

60 W.-H. Shih, W. Y. Shih, S.-I. Kim, J. Liu and I. A. Aksay, Phys. Rev. A: At., Mol., Opt. Phys., 1990, 42, 4772.

61 M. C. Grant and W. B. Russel, Phys. Rev. E: Stat. Phys., Plasmas, Fluids, Relat. Interdiscip. Top., 1993, 4, 2606.

62 C. J. Rueb and C. F. Zukowski, J. Rheol., 1997, 41, 197.

63 J. Sapp, Microbiol. Mol. Biol. Rev., 2005, 69, 292.

64 E. C. O’Neill, M. Trick, L. Hill, M. Rejzek, R. G. Dusi, C. J. Hamilton, P. V. Zimba, B. Henrissat and R. A. Field, Mol. BioSyst., 2015, 11, 2808.

65 J. Beardall, A. Johnston and J. Raven, Can. J. Bot., 1998, 76, 1010.

66 J. Livage, T. Coradin and C. Roux, J. Phys.: Condens. Matter, 2011, 13, R673.

67 H. Frenkel-Mullerad and D. Avnir, J. Am. Chem. Soc., 2005, 127, 8077.

68 A. J. Milligan and F. M Morel, Science, 2002, 297, 1848. 